\title{
Biological false positive serological tests for syphilis in the Jamaican population
}

\author{
M F Smikle, O B'L James, P Prabhakar
}

\begin{abstract}
A total of 19067 sera were screened for biological false positive (BFP) reactivity by the Venereal Disease Research Laboratory (VDRL) test. Sera which were reactive in the VDRL test were confirmed by the fluorescent treponemal antibody absorption (FTA-ABS) test. BFP reactions were detected in $0.59 \%$ of the general population, $0.72 \%$ of pregnant women and $11.8 \%$ of patients with systemic lupus erythematosus (SLE). The rate of BFP reactors among pregnant women did not differ significantly from the general population. The female to male ratio of BFP in the general population was $2: 1$ whilst that in the group of patients with SLE was 8:1. The overall seroprevalence of syphilis was $2 \cdot 2 \%$.
\end{abstract}

The best standardised and most widely used nontreponemal, screening test for syphilis is the Venereal Disease Research Laboratory (VDRL) test. ${ }^{12}$ By virtue of the non-specificity of antigen (a mixture of cardiolipin, cholesterol and lecithin) the VDRL may yield "biological false positive" (BFP) results. A BFP test for syphilis ${ }^{3}$ is considered to be a reactive nontreponemal test but a nonreactive treponemal test. BFP tests have been further categorized as "acute" or "chronic". 4 Acute BFP tests disappear within six months and have been reported in pregnancy, drug addiction, following acute infectious diseases and in healthy persons. Chronic BFP tests remain beyond six months sometimes indefinitely and have been reported in rheumatic disorders, dermatological diseases, chronic infectious diseases and healthy persons. ${ }^{47}$ The BFP results encountered in routine screening of the general population are often difficult or impossible to explain and may provide cause for worry or embarrassment to patients. Of even greater importance, a BFP may be the harbinger of an underlying serious disorder. ${ }^{8}$ BFP reactors may be given penicillin repeatedly on the assumption that they have syphilis.

Department of Microbiology, University of the West Indies, Kingston 7, Jamaica

M F Smikle, O B'L James, P Prabhakar
The Treponema pallidum Haemagglutination Assay (TPHA) is the most widely used specific test for syphilis. ${ }^{9}$ Use of this test reduces the number of adequately treated persons who are positive in routine screening for syphilis, as the test usually becomes negative within one to two years in patients who are treated during the primary or early secondary stages of syphilis. ${ }^{10}$ On the other hand, the TPHA is less sensitive than the VDRL in the early primary stage of syphilis and is the most sensitive test for latent syphilis. ${ }^{11}$ The Fluorescent Treponemal Antibody Absorption (FTA-ABS) test may be used to confirm the results of both these tests. ${ }^{12}$

In this laboratory the FTA-ABS test and VDRL are used to confirm the diagnosis of syphilis. Positive treponemal tests in Jamaicans under 40 years of age are considered to be due to syphilis as yaws was eradicated from the island in $1960 .{ }^{13}$ Confirmatory tests for syphilis are available only at the two major urban Jamaican hospitals. The tendency therefore, is to treat all persons, including pregnant women, for syphilis on the basis of the VDRL test alone. In addition rheumatic disorders are fairly common in Jamaica. ${ }^{14}$

The prevalence of BFP VDRL tests in the general population should be established before the level of association with any clinical entity can be accurately assessed. It would also be interesting to assess the clinical accuracy of physicians who do not rely on confirmatory tests in populations such as ours.

In this paper, we report the prevalence of BFP tests in the general Jamaican population, in pregnancy and in cases of systemic lupus erythematosus (SLE).

\section{Patients and methods}

Standard VDRL tests ${ }^{15}$ were performed on sera from 15876 members of the general adult emigrant population, 3039 women attending antenatal clinics throughout the island and 152 patients with systemic lupus erythematosus (SLE).

Sera from SLE patients which were reactive in the VDRL test and sera from the general population and pregnant women which reacted at titres less than 1:8 were further tested by the Fluorescent Treponemal Antibody Absorption (FTA-ABS) test. ${ }^{12}$ 
STATISTICAL ANALYSIS

The Chi-square test was used for data comparisons.

\section{Results}

Of the $15876(2 \cdot 8 \%)$ specimens from the general public 441 were VDRL positive. Of these $94(21.3 \%)$ had titres greater than 1:4. In pregnant women 145 out of $3039(4.7 \%)$ sera were reactive, of which, 70 $(48.2 \%)$ had titres greater than 1:4. (Titres ranged from $1: 8$ to $1: 128$.)

Sera from $94(27 \cdot 1 \%)$ of the general adult population that were VDRL positive and $22(30.9 \%)$ of pregnant women with a positive VDRL gave reactive titres of less than 1:8 while being non-reactive by the FTA-ABS test. On the other hand $18(78.2 \%)$ of VDRL reactive sera from SLE patients gave nonreactive FTA-ABS results. These results are shown in the table. One serum from a patient with SLE had a VDRL titre of $1: 128$, but was non-reactive in the FTA-ABS test.

There was no statistically significant difference between the prevalence of BFP in the general population and that in pregnant women. The prevalence of BFP in SLE patients $18 / 152(11.8 \%)$ was statistically significantly higher than in the general population $94 / 15876(0.59 \%, \mathrm{p}<0.001)$ as well as pregnant women $22 / 3039(0.72 \%, p<0.001)$. The overall seroprevalence of syphilis was $2 \cdot 2 \%$.

\section{Discussion}

Although $0.9 \%$ of persons in the study had VDRL titres greater than $1: 4$ and as high as $1: 128$, none of these persons had clinical manifestations of syphilis at presentation. None had a history of yaws; therefore, all were presumed to be cases of treated or latent syphilis.

The results of this study emphasise the need to perform confirmatory tests for syphilis in the Jamaican population. Thus $27 \cdot 1 \%$ in the general population and $30.9 \%$ in pregnant women of low titred VDRL reactive sera were BFP. Seventy eight per cent of reactive VDRL tests in SLE patients were BFP. None of these patients had history or clinical evidence of treponemal disease. The finding of a BFP

Table Confirmation of reactive VDRL by FTA-ABS

\begin{tabular}{|c|c|c|c|c|}
\hline Group (n) & $\begin{array}{l}\text { Overall } \\
\text { Reactive } \\
V D R L \\
\left(\begin{array}{c}0 \\
0\end{array}\right)\end{array}$ & $\begin{array}{l}\text { No } \\
\text { tested } \\
F T A-A B S\end{array}$ & $\begin{array}{l}F T A-A B S \\
\text { Negative } \\
(\%)\end{array}$ & $\begin{array}{l}\text { BFP } \\
\text { Prevalence } \\
(0,0)\end{array}$ \\
\hline $\begin{array}{l}\text { General population } \\
(15876)\end{array}$ & $441(2 \cdot 7)$ & $347^{\star}$ & $94(27 \cdot 1)$ & 0.59 \\
\hline $\begin{array}{l}\text { Pregnant women } \\
\text { (3039) }\end{array}$ & $145(4 \cdot 7)$ & $71^{\star}$ & $22(30.9)$ & 0.72 \\
\hline $\begin{array}{l}\text { Systemic lupus } \\
\text { erythematosus } \\
(152)\end{array}$ & $23(4)$ & 23 & $18(78 \cdot 2)$ & $11 \cdot 8$ \\
\hline
\end{tabular}

VDRL test with a titre of $1: 128$ in a patient with SLE is unusual. ${ }^{716}$

The overall prevalence of BFP VDRL tests in the general population $0.59 \%$ and pregnant women $(0.72 \%)$ was relatively low and was in keeping with previous studies of unselected populations. ${ }^{617}$ It was interesting that the prevalence of BFP test was not statistically significantly different when pregnant women and members of the general population were compared. Other authors have stated that pregnancy is a cause of BFP results. ${ }^{2}$ Our results do not support this view but rather that of Catteral, who suggests that although many BFP tests are detected during pregnancy, this condition may or may not be the cause of BFP test. ${ }^{7}$

A BFP VDRL test is one of the American Rheumatism Associations (ARA) criteria for diagnosis of SLE. ${ }^{18}$ We observed a high prevalence of BFP in our SLE group (11.8\%), similar to that found in other studies. ${ }^{1920}$ In our series, a BFP test was not associated with any given clinical manifestation in patients with SLE, yet such associations with anticardiolipin antibodies have been reported. ${ }^{21}$

Since all patients with SLE had a BFP test for more than six months and often several years duration, the chronicity of the BFP test was established. Unfortunately, in the general population the BFP VDRL test was not categorised as acute or chronic as these were cases of routine screening for emigration purposes. Acute BFP tests are usually of no significance but chronic tests are associated with several systemic diseases, including malignancies. Chronic BFP tests have been shown to be more frequent and to have more serious implications in women than men as the associated autoimmune diseases tend to be more prevalent in women. ${ }^{348}$ The female to male ratio of BFP tests in our general population group was 2:1 whilst in the SLE group it was 8:1. In pregnant women, every effort should be made to categorise BFP tests as acute or chronic, rather than presume that they are caused by pregnancy.

From this study, we recommend that regardless of titre, confirmatory tests should be performed on all sera with a positive VDRL. All BFP reactors should be followed up and categorised as acute or chronic. Those with chronic BFP results should be investigated for clinical and laboratory indicators of autoimmune or other chronic diseases. These measures would reduce the indiscriminate and inappropriate use of antibiotics. This is of particular importance to patients with autoimmune diseases as there is a greater frequency of penicillin and other hypersensitivity drug reactions in this group. The situation is further complicated by the fact that administration of penicillin has been associated with the onset of symptoms of autoimmune disease. ${ }^{7}$

In summary, confirmatory tests for syphilis should be performed on all Jamaican patients with low titre 
VDRL reactivity, mindful of the relatively high prevalence of conditions associated with BFP reactions.

We thank the Technical Staff, Immunology Section, Dr Shoucair, Medical Assessment, Jamaica, Dr F. Brathwaite, Ministry of Health; and Mrs E. Pessoa and Miss C. Earle for secretarial assistance.

Address for correspondence: M F Smikle, Department of Microbiology, UWI, Mona, Kingston 7, Jamaica

1 Luger A, Schmidt B, Spendlingwimmer I, Horn F. Recent observations on the serology of syphilis. Br J Venereal Dis 1980;56:12-6.

2 Diggory Paul. Role of the Venereal Disease Research Laboratory test in the detection of syphilis. BrJ Venereal Dis 1983;59. 8-10.

3 Moore JE, Mohr CF. Biological false-positive serological tests for syphilis. $J A M A 1952 ; 150 ; 476-3$.

4 Salo OP, Aho K, Nieminer E, Hormulia P. False-positive serological tests for syphilis in pregnancy. Acta Derma Venereol 1969;49:332-7.

5 Gibowski M, Newman E. Nonspecific positive test results to syphilis in dermatological disease. $\mathrm{Br} J$ Venereal Dis 1980;56:17-19.

6 Kaufman RE, Weiss S, Moore JD, Falcone V. Wiesner PJ. Biological false positive serological tests for syphilis among drug addicts. Br J Venereal Dis 1974;50:350-3.

7 Catteral RD. Systemic disease and the biological false positive reaction. BrJ Venereal Dis 1972;48:1-12.

8 Long R, Haserick JR. Systemic lupus erythematosus preceded by false positive tests for syphilis. JAMA 1952;150:467-73.

9 Tomizowa $T$, Kasamaton $S$, Yamata $S$. The usefulness of haemagglutination test using Treponema pallidum as antigen for serodiagnosis of syphilis. Jpn J Med Sci Biol 1969;22: 341-5.

10 Fiumara NJ. Treatment of Secondary Syphilis: An evaluation of 204 patients. Sex Transm Dis 1977;4:96-9.

11 Young H, Henrichsen C, Robertson DHH. The TPHA test as a screening procedure for the diagnosis of syphilis. $\mathrm{Br} J$ Venereal Dis 1974;50:341-6.

12 Hunter EF. Deacon ME, Meyer PC. An improved FTA test for syphilis. The absorption procedure (FTA-ABS). Public Health Rep 1964;79:410-12.

13 Ashcroft MT, Urquhart AE. Treponemal serological tests in Jamaican school children, 1976. West Indian Med J 1978; 27:26-9.

14 Wilson WA, Hughes GRV. Rheumatic disease in Jamaica. Ann Rheum Dis 1979;38:320-5.

15 Manual of Tests for Syphilis. Washington: US Department of Health and Welfare Public Health Service, 1969.

16 Yehudi M, Felman MD, James A, Nikitas MA. Syphilis serology today. Arch Dermatol 1980;116:84-9.

17 Hossain A. Serological tests for syphilis in Saudi Arabia. Genitourin Med 1986;62:293-7.

18 Tan EM, Cohen AS, Fries JF, et al. The 1982 American Rheumatism Association revised criteria for the classification of Systemic lupus erythematosus. Arthritis Rheum 1985; 28:693-8.

19 Ryuichi Yard Tokugoro T. Application to Japanese Patients of the 1982 American Rheumatism Association revised criteria for the classification of Systemic lupus erythematosus. Arthritis Rheum 1985;28:693-8.

20 Cohen AS, Reynolds WE, Franklyn EC, et al. Preliminary criteria for the classification of systemic lupus erythematosus. Bull Rheum Dis 1971;21:643-8.

21 Hughes GRV. The Anticardiolipin Syndrome. Clin Exp Rheumatol 1985;3:285-6.

Accepted for publication 24 November 1989. 